\title{
Preparation of diagnostic lysate antigens for rapid evaluation of local entero-3 vaccine
}

\author{
A. A., EI-Kholy', Amal M. EI-Sawah², M. S., Wassel', \\ S. M., Zeidan' ${ }^{1}$ A. M., Daoud ${ }^{1}$ \\ ${ }^{1}$ Veterinary Serum and Vaccine Researches Institute, Abbassia, Cairo, Egypt. \\ ${ }^{2}$ Central Laboratory for Quality control of Veterinary Biologics, Abbassia, Cairo, Egypt
}

\begin{abstract}
Studies were conducted to determine the utility of lysate antigens for rapid evaluation of the local entero-3 vaccine, antigens were prepared from cell cultures infected with bovine rota virus (BRV) and bovine corona virus (BCV) as well as from Enterotoxigenic E. coli strain K99. Prepared antigens were tested with field serum samples collected from both late pregnant entero-3 vaccinated cows and their offsprings using different serological assays including: microagglutination test, indirect ELISA and immunofluorescent antibody technique. Results of this endeavor were correlated to that of the standard virus neutralization test. The locally prepared antigens were proved useful for vaccine evaluation. Moreover, these antigens are recommended for both detection and assessment post vaccination or post infection of sero-conversion against $\mathrm{BRV}, \mathrm{BCV}$ and $E$. coli.
\end{abstract}

The first few weeks in the life of newborn calves are considered the most critical period, during which a considerable number of animals can be lost. Neonatal calf diarrhea remains one of the most important disease problems facing livestock production, causing great economic losses every year in Egypt and worldwide (Acres et al., 1986 and Mortin et al., 1978). The etiology of neonatal calf diarrhea is a multifactorial complex involving many infectious agents. Bovine rota virus (BRV) and Bovine corona virus (BCV) being the most dominant causative agent in combination with the enterotoxigenic E. coli (Sondgrass et al., 1986 and Saif and Thiel, 1990).

In Egypt, bovine rotavirus was isolated for the first time by Shalaby et al., (1981), from faeces of newborn diarrheic calves. Since that time, many studies were conducted to assess the incidence of infection (Shalaby et al., 1987; Iman et al., 1995 and Perk et al., 2000). Previous studies proved that the incidences of pathogens affecting bovine neonates in Egypt were BRV (37.3\%), BCV (18.2\%) and E. coli $(25.4 \%)$ (Farid et al., 1992) and 19.1\% for others such as Clostridia, Cryptosporidia and non-infectious causes including environmental, managements, hygienic and nutritional factors (Perk et al., 2000). If calves are infected at birth, it is almost impossible to actively immunize them prior to their exposure to virulent field virus. Therefore, the best way to reduce economic losses among neonatal calves is to vaccinate dams at late pregnancy thus increasing their colostral antibody level that is passively transferred to suckling calves (Saif et al., 1983).

Currently, some inactivated vaccines, containing BRV, BCV and E. coli $\mathrm{K} 99$, are used in the Egyptian field either prepared locally e.g. Entero-3 (Daoud et al., 2003) or imported e.g. Scour-Guard. Traditional evaluation of such vaccines requires special procedure for both viral and bacterial antigens, which are complicated, time consuming, laborious and expensive.

The present work aimed to save time, effort and expenses using simple approach for preparation of reliable $\mathrm{BRV}, \mathrm{BCV}$ and $E$. coli lysate antigens such antigens could be utilized in microagglutination, indirect ELISA and immunofluorescent antibody techniques for rapid and accurate evaluation of the vaccine.

\section{Material and Methods}

Viruses and cells. The local isolate of bovine rotavirus (Shalaby et al., 1981) with a titer of $10^{6.7} \mathrm{TCID}_{50}$ and the reference bovine corona virus (Nebraska strain, with a titer of $10^{6.0}$ $\mathrm{TCID}_{50}$ ) were used. Both virus entities were propagated and titrated on Madin-Darby Bovine Kidney (MDBK) cell culture. The MDBK cells were grown at $37^{\circ} \mathrm{C}$, in minimum essential medium with Earle's salts (MEME) supplement with $10 \%$ fetal calf serum. Prior to experimental work, both viruses were tested for their identity by serum neutralization test and indirect immunoflourescent antibody technique (Palmer et al., 1982) using the respective specific 
reference antisera (Glasgow Animal Clinic, Bacterial strain. Reference strain of the enterotoxigenic E. coli strain K99 was used in this study. Bacterial Strain (E. coli K99) was identified by the microagglutination test (Collins et al., 1988) using the respective monoclonal antiserum (Glasgow Animal Clinic, Kentucky, USA).

Animals and serum samples. Ten late pregnant Holstein cows, in private dairy farm at ElNubarria, Alexandria in addition to their offspring calves $(n=10)$ were used in this study. Before vaccination, cows were proved seronegative to $\mathrm{BRV}$ and $\mathrm{BCV}$ by virus neutralization test (Dauvergene et al., 1983) and to $E$. coli by microagglutination test (Collins et al., 1988). They were vaccinated twice with the local inactivated entero- 3 vaccine at 8 and 5 weeks before parturition. All cows and their offsprings were clinically normal throughout the experimental period. Serum samples were collected from vaccinated cows at the times of $1^{\text {st }}$ vaccination zero time, $2^{\text {nd }}$ vaccination and calving. Offspring calves were bled on the $1^{\text {st }}$, $2^{\text {nd }}$ and $3^{\text {rd }}$ weeks post natal (after parturition).

Preparation of bovine rota and corona lysate antigens. Confluent monolayers of MDBK cells grown in Roux bottles were inoculated separately with BRV and BCV at multiplicity of infection of 1 (m.o.i $=1)$, and incubated at $37^{\circ} \mathrm{C}$, in the presence of $1 \mathrm{mg} / \mathrm{ml}$ of trypsin. When about $65-75 \%$ of infected cells showed CPE, the culture fluid was removed and virus-infected cells were solubilized directly with lysis buffer. The translucent cell lysate was scraped off, transferred into clean strile tubes, sonicated on ice at $60 \%$ intensity and clarified by low speed cooling centrifugation. The whole virus cell lysate (WVCL) were kept at $-20^{\circ} \mathrm{C}$ until used.

Preparation of $\boldsymbol{E}$. coli lysate antigen. As an attempt to solubilize all possible immunoreactive antigenic components, the $E$. coli strain K99 was grown in its selective media (Minca-Vitox medium and trypticase soya broth). Growth continued for $24 \mathrm{~h}$ at $37^{\circ} \mathrm{C}$ and the bacterial cells were collected by centrifugation at $6000 \mathrm{rpm}$, $4^{\circ} \mathrm{C}$ for $30 \mathrm{~min}$. The bacterial cell pellets were washed twice in sterile normal saline then, solubilized with lysis buffer thus producing translucent lysates. The whole bacterial cell lysates (WBCL) were kept at $-20^{\circ} \mathrm{C}$ until used.

Virus neutralization test (VNT). The VNT was conducted for standard evaluation of seroconversion of late pregnant cows and their offsprings following local Entero-3 vaccination.
Kentucky, USA).

All sera were assayed for presence of specific antibodies to BRV and BCV in 96-well flatbottom tissue culture plates (Nunc.) following the procedure described by Dauvergene et al., (1983). The virus neutralizing antibody (VN-Ab) titers of serum samples were expressed as $\log _{10}$ of the reciprocal serum dilution that protected $\geq$ $50 \%$ of microtitration plate wells following the calculation procedure of (Reed and Muench, 1938).

Microagglutination test (MAT). This test was done as was described by (Collins et al., 1988) for determination of anti-E. coli strain K99 antibody titers.

Indirect Immunofluorescent assay (IFA). The IFA technique was carried out in a duplicate per serum sample according to (Palmer et al., 1982) with some modifications. Briefly, the slide wells were coated separately with the BRV, BCV and E. coli k99 lysate antigens, air-dried, reacted with serum samples for $1 \mathrm{~h}$ at $37^{\circ} \mathrm{C}$, and probed with fluorescein isothiocyanate (FITC, Sigma) labeled anti-bovine $\operatorname{IgG}$ (diluted to 1:50 in Phosphate buffer saline (PBS, $\mathrm{pH}$ 7.6). The slides were mounted with glycerol (4:1 in PBS) and examined microscopically for greenish yellow fluorescence using a fluorescence microscope. A sample was considered positive when at least two virus-specific fluorescent cells were observed in any slide well.

Indirect enzyme-linked immunosorbent assay (ELISA). ELISA was applied according to methods described by (Rose et al., 1986). 96well flat-bottomed ELISA plates (Immunoblon 1) were coated separately with $100 \mu \mathrm{l}$ of the $\mathrm{BRV}, \mathrm{BCV}$ and E. coli k99 lysate antigens, adjusted to concentrations of $0.6 \mathrm{mg} / \mathrm{ml}$ in carbonate-bicarbonate buffer $(\mathrm{pH}$ 9.6) for each and kept overnight at $4^{\circ} \mathrm{C}$. Serum samples $(\mathrm{n}=60)$, diluted 1:10 in PBS $(\mathrm{pH} 7.4)$, were added as $100 \mu \mathrm{l} /$ well in duplicates for each. Each plate contained positive and negative sera as well as a blank control. After an hour incubation at $37^{\circ} \mathrm{C}$, PBS ( $\mathrm{pH} \mathrm{7.4)} \mathrm{washing} \mathrm{of} \mathrm{the}$ plates, a $100 \mu \mathrm{l} /$ well of the horse radish peroxidase labeled anti-bovine IgG conjugate was added to each well and allowed to react for $1 \mathrm{~h}$ at $37^{\circ} \mathrm{C}$. A freshly prepared, ortho-phenylene diamine, (sigma) substrate working solution was added (50 $\mu \mathrm{l} /$ well). Plates were incubated at $37^{\circ} \mathrm{C}$ for $15 \mathrm{~min}$., with gentle agitation in dark place. The reaction was halted by adding 50 $\mu \mathrm{l} /$ well of $1.25 \mathrm{M}$ sulphuric acid and the optical density (OD) was estimated at wave length 
of 490 nanometer using the microplate ELISA auto-reader (Dynatech). The cut off mean absorbance values for $\mathrm{BRV}, \mathrm{BCV}$ and $E$. coli k99 lysate antigens were $0.06,0.03$ and 0.07 respectively

\section{Results and Discussion}

Neonatal calf diarrhoea represents an important cumbersome, exerting an economic impact on bovine industry worldwide (Radostitis, 1991), including Egypt (Shalaby et al., 1981; Kassem et al., 1995 and Perk et al., 2000). Currently, a trivalent inactivated vaccine (either the local entero-3 or the imported Scour gaurd), containing $\mathrm{BRV}, \mathrm{BCV}$ and E. coli $\mathrm{K} 99$, is being used in Egypt for immunization of late pregnant cows to passively protect their offsprings via the elicited colostral antibodies. Traditional evaluation of such vaccines depends mainly on virus neutralization test (VNT) which is considered the standard test. However, it is gradually being replaced by ELISA and fluorescent antibody technique that offered advantages of rapid results and reduced costs (Rose et al., 1986). In the present endeavor, reliable $\mathrm{BRC}, \mathrm{BCV}$ and $E$. coli lysate antigens were prepared using simple procedure antigen lysates are utilized in microagglutination, indirect ELISA and immunofluorescent antibody techniques for rapid evaluation of such vaccines, versus the standard VNT.

Post-vaccination seroconversion of late pregnant cows and their offsprings, vaccine was monitored by VNT (Table 1). Results revealed that virus neutralizing antibody (VN-Ab) titers elicited against BRV and BCV were increased by the $2^{\text {nd }}$ week post-vaccination $\left(\log _{10}\right.$ mean $\mathrm{VN}-\mathrm{Ab}$ titer was 1.68 for both viruses), reaching the highest titer (2.28 and 2.37 for BRV and $\mathrm{BCV}$, respectively) by the calving time. The present results are in agreement with that obtained by (Daoud et al., 2003 and Mahmoud and Zeidan, 2004). They concluded that there was a remarkably increase in the mean neutralizing antibody titers by the time of the $2^{\text {nd }}$ dose that sharply increased by the time of parturition. Offsprings of vaccinated cows were passively seroconverted to $\mathrm{BRV}$ and $\mathrm{BCV}$ exhibiting high $\mathrm{VN}-\mathrm{Ab}$ titers during the experimental period (Table 1). These results were in harmony with that obtained by (Daoud et al., 2003) who concluded that VN-Ab titers of the newly born calves were sharply increased after ingestion of colostrum from entero-3 vaccinated cows. Saif et al. (1983) postulated that lactogenic immunity plays a significant role

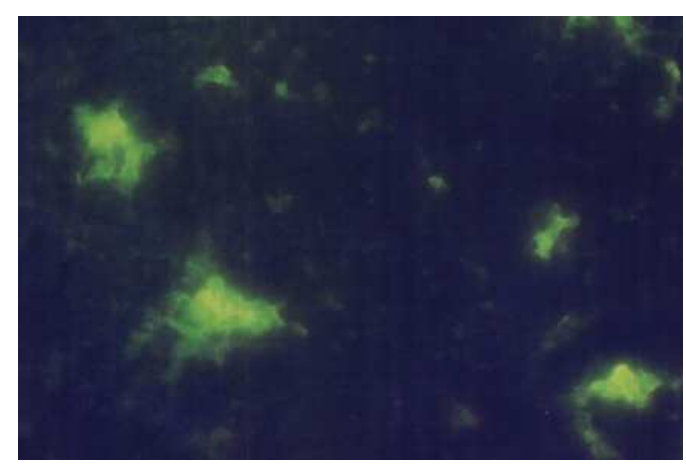

Fig. (1): Indirect immunofluorescent antibody technique. Positive results showing specific fluorescent cytoplasmic granules.

in protection of calves against infection.

Results of VNT (Table 1) were in accordance with that obtained by ELISA on testing the same serum samples (Table 3), using the locally prepared BRV and BCV lysate antigens. Accordingly, ELISA could be used for evaluation of the entero-3 vaccine utilizing these antigens. Mean anti-E. coli agglutinating antibody titers of entero-3 vaccinated cows and their offsprings, using the E. coli lysate antigen in microagglutination test (MAT), were illustrated in Table (2). It was evident that the vaccinated cows and their offsprings remained with high anti-E. coli agglutinating antibody titers throughout the experiment. The MAT results were parallel to the ELISA results (Table $3)$. These results coincided with that reported by (Collins et al., 1988 and Daoud et al., 2003 and 2005) who reported that mean anti-E. coli agglutinating antibody titers of vaccinated cows increased by the $4^{\text {th }}$ week post-vaccination and reached their maximal titers by the $6^{\text {th }}$ week post-vaccination. Detection of specific antibodies against the prepared BRV, BCV and E. coli K99 lysate antigens using indirect immunoflurescent antibody technique (IFA) was satisfactory (Table 4, Fig. 1). The IFA gave discrete positive results with sera of the vaccinated cows and their offsprings. These results were supported with that obtained by VNT, indirect ELISA and microagglutination tests.

In conclusion, locally prepared lysate antigens, from BRV and BCV infected MDBK cells as well as from E. coli K99 bacterial cells, are economic and reliable for rapid evaluation of entero-3 vaccine. Nevertheless, they are recommended for both detection and assessment of post-vaccination or post-infection antibodies against $\mathrm{BRV}, \mathrm{BCV}$ and $E$. coli. 
Table (1): Virus neutralizing antibody (VN-Ab) titres expressed as $\log _{10}$ against bovine rota virus (BRV) and bovine corona virus (BCV) in sera of entero-3 vaccinated late pregnant cows and their offsprings using viral lysate antigens.

\begin{tabular}{|c|c|c|c|c|c|c|c|c|c|c|c|c|}
\hline \multirow{4}{*}{ Cows No. } & \multicolumn{12}{|c|}{$\log _{10} V N-A b$} \\
\hline & \multicolumn{6}{|c|}{ Pregnant cows } & \multicolumn{6}{|c|}{ Offspring calves } \\
\hline & \multicolumn{2}{|c|}{$1^{\text {st }}$ vaccination } & \multicolumn{2}{|c|}{$2^{\text {nd }}$ vaccination } & \multicolumn{2}{|c|}{ Calving } & \multicolumn{2}{|c|}{$1^{\text {st }} W P P$} & \multicolumn{2}{|c|}{$2^{\text {nd }} W P P$} & \multicolumn{2}{|c|}{$3^{\text {rd }} W P P$} \\
\hline & BRV & BCV & BRV & BCV & BRV & BCV & BRV & BCV & BRV & BCV & BRV & $\mathbf{B C V}$ \\
\hline 1 & 0.3 & 0.3 & 1.8 & 1.5 & 2.4 & 2.1 & 2.1 & 2.1 & 1.8 & 1.8 & 1.5 & 1.5 \\
\hline 2 & 0.3 & 0.0 & 1.5 & 1.5 & 2.1 & 2.4 & 1.8 & 2.1 & 1.5 & 1.8 & 1.2 & 1.2 \\
\hline 3 & 0.6 & 0.3 & 1.8 & 1.8 & 2.4 & 2.4 & 1.8 & 1.8 & 1.8 & 1.5 & 1.5 & 1.2 \\
\hline 4 & 0.3 & 0.3 & 1.5 & 1.5 & 2.1 & 2.1 & 1.8 & 1.8 & 1.8 & 1.5 & 1.5 & 0.9 \\
\hline 5 & 0.9 & 0.3 & 1.8 & 1.8 & 2.4 & 2.4 & 2.1 & 2.1 & 1.8 & 1.8 & 1.8 & 1.8 \\
\hline 6 & 0.3 & 0.3 & 2.1 & 1.8 & 2.7 & 2.4 & 1.8 & 2.1 & 1.5 & 1.8 & 1.2 & 1.5 \\
\hline 7 & 0.6 & 0.6 & 1.5 & 2.1 & 2.1 & 2.7 & 1.8 & 2.4 & 1.5 & 2.1 & 1.2 & 1.8 \\
\hline 8 & 0.0 & 0.3 & 1.5 & 1.5 & 2.1 & 2.4 & 1.5 & 2.1 & 1.2 & 1.8 & 0.9 & 1.5 \\
\hline 9 & 0.3 & 0.3 & 1.8 & 1.5 & 2.4 & 2.4 & 2.1 & 1.8 & 1.8 & 1.5 & 1.2 & 1.2 \\
\hline 10 & 0.3 & 0.3 & 1.5 & 1.8 & 2.1 & 2.4 & 1.8 & 1.8 & 1.5 & 1.5 & 1.2 & 1.2 \\
\hline Mean & 0.39 & 0.3 & 1.68 & 1.68 & 2.28 & 2.37 & 1.86 & 2.01 & 1.62 & 1.71 & 1.32 & 1.38 \\
\hline
\end{tabular}

WPP: Weeks Post Parturition

Table (2): Anti-E. coli K99 microagglutinating antibody titres in sera of entero-3 vaccinated pregnant cows and their offsprings as determined by microagglutination test (MAT) using bacterial cell lysate antigen.

\begin{tabular}{|c|c|c|c|c|c|c|}
\hline \multirow{3}{*}{$\begin{array}{l}\text { Animal } \\
\text { number }\end{array}$} & \multicolumn{6}{|c|}{ Microagglutinating antibody titers } \\
\hline & \multicolumn{3}{|c|}{ Pregnant cows } & \multicolumn{3}{|c|}{ Offspring calves } \\
\hline & $1^{\text {st }}$ vacc. & $2^{\text {nd }}$ vacc. & Calving & $\mathbf{1}^{\text {st }} \mathbf{W P P}$ & $2^{\text {nd }} W P P$ & $3^{\text {rd }} W P P$ \\
\hline 1 & 16 & 512 & 1024 & 1024 & 1024 & 512 \\
\hline 2 & 16 & 256 & 512 & 2048 & 1024 & 512 \\
\hline 3 & 32 & 512 & 1024 & 1024 & 1024 & 512 \\
\hline 4 & 16 & 256 & 512 & 1024 & 1024 & 512 \\
\hline 5 & 16 & 256 & 512 & 1024 & 512 & 512 \\
\hline 6 & 64 & 512 & 1024 & 2048 & 1024 & 1024 \\
\hline 7 & 16 & 256 & 512 & 1024 & 512 & 512 \\
\hline 8 & 8 & 256 & 512 & 1024 & 512 & 512 \\
\hline 9 & 16 & 512 & 1024 & 1024 & 1024 & 512 \\
\hline 10 & 16 & 512 & 1024 & 1024 & 1024 & 512 \\
\hline Mean & 21.6 & 384 & 768 & 1228.8 & 870.4 & 563.2 \\
\hline
\end{tabular}




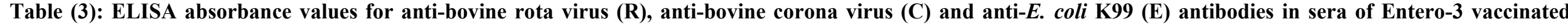
pregnant cows and their offsprings using prepared lysate antigens

\begin{tabular}{|c|c|c|c|c|c|c|c|c|c|c|c|c|c|c|c|c|c|c|}
\hline \multirow{3}{*}{$\begin{array}{l}\text { Tested } \\
\text { Animal } \\
\text { No. }\end{array}$} & \multicolumn{9}{|c|}{ Pregnant cows } & \multicolumn{9}{|c|}{ Offspring calves } \\
\hline & \multicolumn{3}{|c|}{$1^{\text {st }}$ vaccination } & \multicolumn{3}{|c|}{$2^{\text {nd }}$ vaccination } & \multicolumn{3}{|c|}{ Calving } & \multicolumn{3}{|c|}{$1 \mathrm{WPP}$} & \multicolumn{3}{|c|}{2 WPP } & \multicolumn{3}{|c|}{3 WPP } \\
\hline & $\mathbf{R}$ & $\mathbf{C}$ & $\mathbf{E}$ & $\mathbf{R}$ & $\mathbf{C}$ & $\mathbf{E}$ & $\mathbf{R}$ & $\mathbf{C}$ & $\mathbf{E}$ & $\mathbf{R}$ & $\mathbf{C}$ & $\mathbf{E}$ & $\mathbf{R}$ & $\mathbf{C}$ & $\mathbf{E}$ & $\mathbf{R}$ & $\mathbf{C}$ & $\mathbf{E}$ \\
\hline 1 & 0.06 & 0.02 & 0.06 & 0.265 & 0.231 & 0.283 & 0.333 & 0.299 & 0.301 & 0.311 & 0.282 & 0.306 & 0.292 & 0.231 & 0.261 & 0.281 & 0.201 & 0.250 \\
\hline 2 & 0.03 & 0.03 & 0.05 & 0.311 & 0.301 & 0.311 & 0.459 & 0.391 & 0.351 & 0.397 & 0.299 & 0.311 & 0.295 & 0.261 & 0.276 & 0.275 & 0.250 & 0.246 \\
\hline 3 & 0.02 & 0.02 & 0.07 & 0.261 & 0.231 & 0.251 & 0.321 & 0.231 & 0.351 & 0.310 & 0.276 & 0.315 & 0.231 & 0.211 & 0.241 & 0.221 & 0.201 & 0.231 \\
\hline 4 & 0.04 & 0.03 & 0.03 & 0.273 & 0.221 & 0.241 & 0.352 & 0.261 & 0.357 & 0.231 & 0.210 & 0.221 & 0.231 & 0.221 & 0.241 & 0.211 & 0.211 & 0.232 \\
\hline 5 & 0.04 & 0.02 & 0.06 & 0.241 & 0.201 & 0.231 & 0.310 & 0.311 & 0.352 & 0.311 & 0.310 & 0.322 & 0.251 & 0.202 & 0.215 & 0.231 & 0.200 & 0.205 \\
\hline 6 & 0.03 & 0.03 & 0.05 & 0.262 & 0.210 & 0.251 & 0.395 & 0.351 & 0.321 & 0.373 & 0.309 & 0.312 & 0.253 & 0.221 & 0.231 & 0.236 & 0.203 & 0.222 \\
\hline 7 & 0.03 & 0.03 & 0.06 & 0.275 & 0.241 & 0.255 & 0.386 & 0.364 & 0.351 & 0.365 & 0.342 & 0.312 & 0.239 & 0.201 & 0.225 & 0.219 & 0.190 & 0.210 \\
\hline 8 & 0.03 & 0.03 & 0.03 & 0.282 & 0.231 & 0.244 & 0.361 & 0.321 & 0.331 & 0.341 & 0.337 & 0.339 & 0.232 & 0.221 & 0.231 & 0.207 & 0.203 & 0.207 \\
\hline 9 & 0.06 & 0.03 & 0.03 & 0.371 & 0.302 & 0.357 & 0.446 & 0.396 & 0.399 & 0.411 & 0.397 & 0.339 & 0.295 & 0.282 & 0.276 & 0.281 & 0.270 & 0.250 \\
\hline 10 & 0.02 & 0.02 & 0.05 & 0.397 & 0.321 & 0.361 & 0.496 & 0.354 & 0.396 & 0.455 & 0.337 & 0.371 & 0.282 & 0.262 & 0.253 & 0.240 & 0.240 & 0.233 \\
\hline Mean & 0.036 & 0.026 & 0.049 & 0.294 & 0.249 & 0.279 & 0.386 & 0.328 & 0.351 & 0.351 & 0.310 & 0.315 & 0.260 & 0.231 & 0.245 & 0.241 & 0.217 & 0.229 \\
\hline
\end{tabular}

WPP $=$ week post parturition

Table (4): Detection of anti-bovine rota virus (BRV), anti-bovine corona virus (BCV) and anti-E. coli K99 (E) antibodies in sera of entero-3 vaccinated pregnant cows* and their offsprings $* *$ by indirect immunofluorescent antibody technique (IFA)using prepared lysate antigens.

\begin{tabular}{cccc}
\hline Examined sera & Number of samples & Positive IFA & BCV \\
\cline { 2 - 3 } Cows' sera* & 15 & BRV & 15 \\
Offsprings' sera** & 5 & 5 & 5 \\
Cumulative positive percentage & & 5 & $20 / 20=100 \%$ \\
\hline
\end{tabular}

\footnotetext{
$*=$ Randomly selected serum samples collected at the times of $2^{\text {nd }}$ vaccination and calving.
}

** $=$ Randomly selected serum samples collected at the time of $2^{\text {nd }}$ week post-natal. 


\section{References}

Acres, S. D.; Makarechian, M.; Hurk, J. V.; Van-den; Arthur, P. F.; Kubisch, H. M. and Van den Hurk, J. V. (1986): Vaccination of heifers for calf scours caused by Rotavirus and Corona virus. $65^{\text {th }}$ Annual Feeders Day Report, Univ. Aberta, Canda. pp. 19-21.

Collins, N. F.; Halbur, T.; Schwenck, W. H.; Hoogeveen, P.; Pierce R. L.; Behan R. W. and Pankratz, P. (1988): Duration of immunity and efficacy of an oil emulsion E. coli bacteria in cattle. Am. J. Vet. Res., 49 (5): 674-677.

Daoud A. M.; Zeidan, S. M.; Wassel M. S.; Geres S. M. and El-Sayed, E. (2003): Evaluation and field application of locally prepared combined inactivated Rota/Corona viruses and $E$. coli $\mathrm{K}_{99}$ (entero-3 vaccine). $7^{\text {th }}$ Sci. Cong. Egypt. Soc. Cattle dis., Assiut, Egypt, pp. 257-270.

Daoud, A. M.; Diab, R. A.; Aboul Saoud, S. M.; Zeidan, S. M. and Zaki, F. F. (2005): Preparation and evaluation of combined inactivated vaccine containing Rota, Corona viruses, Escherichia coli bacterin and Clostridium perfringens Type "C" toxoid (entero-4): Under Press.

Dauvergene, M. L.; Laporte, G.; Reymoud, P.; Soulebot, A. B. and Espinasse, J. (1983): Vaccination of dams with a combined rota virus, corona virus vaccine to protect new born calves against diarrhoea. Proc. $4^{\text {th }}$ Int. Symp. Neonatal diarrhoea, VIDO, Saskatchewan, Canada, pp. 424-432.

Farid, A. F.; Saad, M. K. and Kaldas, Y. T. (1992): Causes of mortality of newborn calves in some farms in Egypt. Proc. Sci. Cong., Fac. Vet. Med., Assiut Univ., pp. 81-87.

Kassem, K. A.; Wassel, M. S.; Zeidan, S. M. and ElEbiary, E. (1995): A serologic survey of bovine Rotavirus infection. Assiut Vet. Med. J., 34 (67): 26-95.

Mahmoud, M. F. and Zaidan, S. M. (2004): Studies for preparation of combined inactivated vaccine containing Rota, Corona viruses and toxoid of Clostrodium perfringens type "C". $1^{\text {st }}$ Sci. Conf. Fac. Vet. Med., Moshtohor, Benha, Egypt, pp. 1-4.
Mortin, M.; Larivere, S. and Lallier, R. (1978): Pathology and microbiology of spontaneous causes in diary herds and incidence of the enteropathogens implicated as etiological agents. Proc. $2^{\text {nd }}$ Int. Symp. Neonatal Diarrhoea, pp. 397-367.

Palmer, D. G.; Pohtenz J. F. L. and Werlenmam R. P. (1982): Demonstration of Rotavirus antigen in Trypsin digested paraffin tissue sections by immunofluorescence. Am. J. Vet. Res., 43: 1089-1091.

Perk, K.; Moussa, A. A.; Tromp, A. M.; Reda, I. M.; Rafai, M.; Friedman, A.; Farid, A. F.; Gallily, O.; Salah, S. M. and Saif, L. (2000): Neonatal diarrhoeal disease of dairy cattle in Egypt and Israel. Israel Vet. Med. Assoc., 55 (1): 1-7.

Radostits, O. M. (1991): The role of management and use of vaccines in the control of acute undifferentiated diarrhea of newborn calves. Can. Vet., 32: 155-159.

Reed, L. J. and Muench, H. (1938): A simple method of estimating fifty percent end points.

Am. J. Hyg., 27: 493-497.

Rose, V.; Freidman, H. and Fahey, J. (1986): Enzyme linked immunosorbent assay. Manual Clin. Lab. Immunol., Am. Soc. Microbiol., Washington, D.C. pp. 107-109.

Saif L. J. and Theil, K. W. (1990): Viral diarrhea of man and animals. Boca Raton. DT. C.RC Press.

Saif, I. J.; Redman, D. R.; Smith, K. L. and Theil, K. W. (1983): Passive immunity to bovine rota-virus in new born calves fed colostrums supplemented from immunized or non-immunized cow. Infect. Immun., 411: 1118-1131.

Shalaby, M. A.; Saber, M. S. and El-Karmany, R. M. (1981): Rotavirus infection associated with diarrhoea in calves. Egypt. Vet. Res. Comm., 5: 165-170.

Shalaby, A. A.; Karim, I. A.; Sokkar, S. M.; Shehata, H. A. and Reda, I. M. (1987):

Isolation bovine Rotavirus from calves in Kalliobia. J. Egypt. Vet. Med. Assoc., 47 (12): 209-218.

Sondgrass, D. R.; Terzolo, H. R. and D. Sherwood (1986): Aetiology of diarrhea in young calves. Vet. Rec., 119: $31-34$ 